\title{
Report on the First IGU-AGLE Commission Conference on Global Rural Development and Land Capacity Building
}

\author{
YANG Yuanyuan, LI Yuheng, LONG Hualou \\ Institute of Geographic Sciences and Natural Resources Research, CAS, Beijing 100101, China
}

\section{Background of the conference}

Urbanization is one of the major land use and land cover changes sweeping the globe. Rural decline has inevitably accompanied with the increasing global levels of urban development. Emerging rural issues have swept both developing and developed countries and hindered rural sustainability, including rural depopulation and exodus, abandoned land, rural poverty, industrial recession, culture decline, and environmental pollution. As a result, the development capacity of rural areas has fallen and threatened their sustainability and resilience. Changing socio-economic and climate conditions pose great challenges to global food security, rural sustainability and poverty reduction.

The transformation of human socio-economic activities associated with rural decline also exerts further impacts on land use changes in these areas, such as farmland loss, land use inefficiency and abandoned residential land. Thus, the enhancement of land capacity plays an important role in coordinating the man-land relationship and sustaining rural development and food security globally. Generally, land capacity refers to a collective term covering land potential, capacity and function, which is a comprehensive embodiment of natural potential, economic value, ecological function, social security and technical contribution of land in a given region. Land capacity construction aims to construct high standard farmland, guarantee land sustainable utilization, and promote agricultural security and rural sustainable development using land engineering technology ${ }^{1}$. It will provide scientific basis for related planning decision of land use and rural sustainable development from typical cases and key areas to national even global scale. Meanwhile, traditional agricultural geography and land use research need to change the research methods and it is necessary to widely use modern engineering technology and big data to establish scientific, technical, strategic and policy-implicated systems, respectively. Agricultural land engineering provides an effective way to discover, adapt and recreate the new function of sustainable land-use system in the new-era, and it is an important guarantee to solve the obstacles of agriculture and to achieve sustainable rural development.

The conference on Global Rural Development and Land Capacity Building is an inaugural one of the International Geographical Union Commission on Agricultural Geography and Land Engineering (IGU-AGLE), which was formally established in late 2016. The ambition of this commission is deeply embedded in the changing socio-economic, environmental and climate conditions which have posed great challenges to the global food security and poverty reduction. The conference is to analyze rural decline and investigate the relationship between rural transformation development and land use with a view to contributing to sustainable agriculture and rural development.

\footnotetext{
1 Liu Yansui. Land Engineering for Agricultural Sustainability: From China to the World. Abstract Book of the First IGU-AGLE Commission Conference on Global Rural Development and Land Capacity Building (2017-08).
} 


\section{Overview of the conference}

The inaugural IGU-AGLE Commission Conference on Global Rural Development and Land Capacity Building was successfully held on 26th-29th August, 2017 in Yulin, China. The conference was organized by IGU-AGLE, Institute of Geographic Sciences and Natural Resources Research (IGSNRR), CAS, and Beijing Normal University. It was co-organized by the Geographical Society of China (GSC), Yulin Municipal Government, Yulin University, Academician \& Expert Workstation of Yulin University, Yulin Academy of Agricultural Sciences, Center for Regional Agriculture and Rural Development (CRARD), IGSNRR, CAS, China Urban-Rural Development Think Tank Alliance, Center for Assessment and Research on Targeted Poverty Alleviation, CAS, Key Laboratory of Degraded and Unused Land Consolidation Engineering, Ministry of Land and Resources of China, Journal of Rural Studies, and Journal of Geographical Sciences. This conference aims to build an international platform for strengthening academic exchanges, promoting international cooperation, and comprehensively advancing the new pattern of global rural development and land capacity building.

Yukio Himiyama, President of the IGU, and Michael Woods, the editor-in-chief of Journal of Rural Studies, sent the congratulation letters, respectively. There were more than 240 participants who registered for the conference from over 50 universities and research institutions. The participants came to Yulin from 17 countries and regions, including China, South Africa, Australia, Sweden, France, the US, India, Pakistan and Hongkong, etc. This general theme was rendered through five specific themes, i.e., rural transformation and governance, rural economic and environmental sustainability, land engineering and modern agriculture, land use and land cover change, and poverty reduction and rural inclusive growth. Abstract book of the inaugural IGU-AGLE Commission Conference on Global Rural Development and Land Capacity Building, was also edited and prepared for this conference.

\section{Opening ceremony}

The opening ceremony was hosted by Prof. Hualou Long, deputy director of the CRARD. Bojie Fu, President of GSC, Academician of CAS, Director of the Department of Earth Sciences at National Natural Science Foundation of China (NSFC), Michael E. Meadows, Secretary-General and Treasurer of the IGU, Xiulan Ma, Vice Mayor of Yulin Municipal People's Government, Jinghong Xu, President of Yulin University, Holly Barcus, Chair of IGU-CSRS Commission, Yansui Liu, Chair of the conference organizing committee and Chair of IGU-AGLE Commission, delivered opening addresses and welcome addresses, respectively. Experts and scholars from both home and abroad concur that attention should be paid to the time, international and strategic

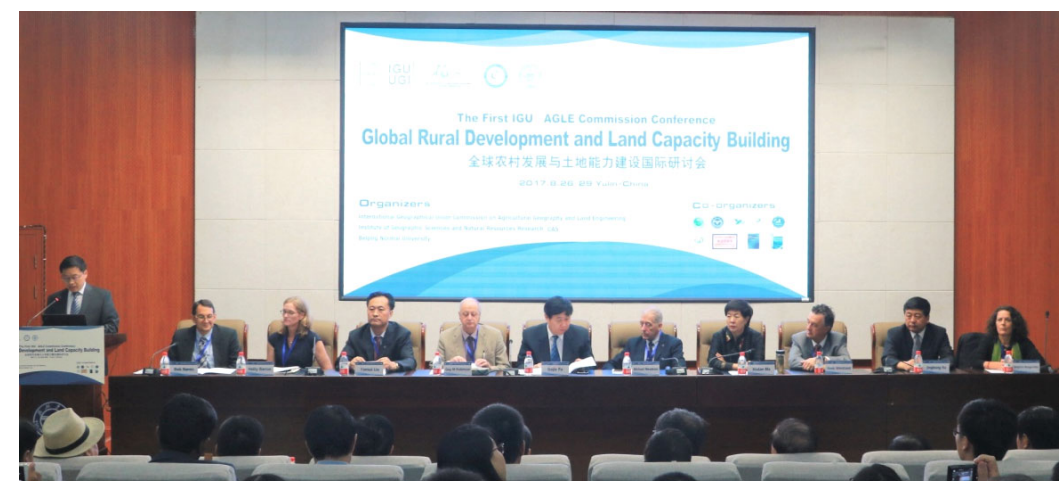

The opening ceremony of conference

Left to right: Hualou Long, Bob Nanes, Holly Barcus, Yansui Liu, Guy M. Robinson, Bojie Fu, Michael E. Meadows, Xiulan Ma, Hans Westlund, Jinghong Xu, Brigitte Nougarèdes 
nature of global rural development and land capacity building, and the problem of global rural decline and land degradation should be specially noticed. It is essential to enhance the frontier, systematicness and urgency of international cooperation research.

\section{Keynote speeches and parallel sessions}

Keynote speeches were presided over by Dr. Yuheng Li, Secretary of IGU-AGLE Commission. Michael E. Meadows firstly gave a speech entitled "Soil erosion and soil conservation in the wheat belt of the Western Cape Province of South Africa: Historical perspectives, recent trends", which described how the Western Cape appears to have been the verge of economic collapse due to the severity of soil erosion during the 1940s. A case study of the SW Cape wheat-belt was made to analyze the land change from degradation to restoration, and recent strategy implementation of "Grain to grape". Bojie Fu delivered a keynote speech entitled "Understanding China's Ecosystems: Processes, Services and Management", which presented an analysis of current situation of Chinese ecosystems and introduced Chinese Ecosystem Research Network (CERN), and finally discussed the adaptive management strategies aiming at restoring and improving the capability of ecosystems that provide services. Holly Barcus gave a speech entitled "Contested space, contested livelihoods: An overview of two decades of pasture management and land tenure reform in Mongolia", which identified three distinct periods of land tenure debate emerging post-1990 in Mongolia, and drew on an extensive review of policy documents and contemporary literature to consider the multi-scalar implications of rapid national growth on internal population redistribution, land use rights, and the underlying importance of place. Guy M. Robinson gave a speech entitled "Local and global impacts on cherry growing: Examples of rural transformation from Shaanxi Province, China and the Adelaide Hills, South Australia", which analyzed the contrasts and similarities between the two examples in the interplay between the global and the local influences while the Chinese example reflects aspects of the huge transformations affecting the Chinese countryside following the national economic reforms commenced in late 1978. Hans Westlund gave a speech entitled "Transformation of Agriculture and Land-Use in the Post-Urban World: Examples from Sweden and the Stockholm Region", which studied spatial and temporal changes in land use with a focus on the Stockholm metropolitan region by exploring the number and size of agricultural firms, changes in their main activity and trends of diversification and land prices for various types of land and location. Yansui Liu gave a speech entitled "Land Engineering for Agricultural Sustainability-from China to the world". He systematically introduced the research background, the innovation system and integration theory of agricultural geography and land engineering, described the four research stations aiming at degraded-land improvement, gully land consolidation, hollowed village consolidation and poverty alleviation, and proposed the frontiers and research plan on agricultural geography and land engineering. Brigitte Nougarèdes gave a speech entitled "A conceptual framework to analyze social justice issues in farmland preservation and development on the urban fringe in France", which applied the conceptual framework on the case studies and found that French policy alternatives were quite effective regarding land preservation, yet they tend to neglect justice issues and were not effective in resolving other issues such as food security, and impeding the renewal and diversification of farms that would be necessary to develop a multifunctional agriculture and local food systems. Bob Nanes gave a speech entitled "Promotion of local innovation as a support to rural development", which introduced MIT's recent research to establish the importance of promoting local innovation as a support to rural development. Yong Chang gave speech entitled "Research of agricultural sustainable development in agro-pastoral ecotone", which analyzed current problems of agricultural development in the agro-pastoral ecotone of northern China and proposed the sustainable agriculture development measures taking Yulin as the case study.

Five theme-based parallel sessions were set up: rural transformation and governance, rural 
economic and environmental sustainability, land engineering and modern agriculture, land use and land cover change, poverty reduction and rural inclusive growth. And there were totally 85 presentations and 22 posters. In theme 1 "rural transformation and governance", presentations were carried out focusing on rural transformation and its driving forces, spatio-temporal characteristics of rural land use change, behavioral analysis of local actors, rural self-constructed gated community, rural hollowing, etc. As for theme 2 "rural economic and environmental sustainability", participants mainly focused on food security, sustainable agriculture and rural development, rural household's well-being and livelihoods, gender difference and its influence on time-use of off-farm employment, etc. In theme 3 "land engineering and modern agriculture", scholars analyzed the issues such as restriction factors of land development, scale of agricultural operation and technology diffusion, gully land consolidation in loess region, land consolidation potential and technology, etc. As for theme 4 "land use and land cover change", participants researched efficiency of land use transformation, spatio-temporal change of arable land and urban land, land use conflict management and homestead release mechanism, etc. In theme 5 "poverty reduction and rural inclusive growth", scholars discussed the regional characteristics of poverty alleviation, impoverishing factors, poverty reduction mechanism and policy innovation, strategy for rural sustainability, etc. The parallel sessions adopted the ways of academic reports, question discussions and expert reviews, which have achieved good effects.

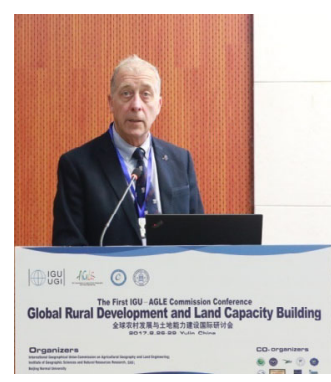

Michael E. Meadows

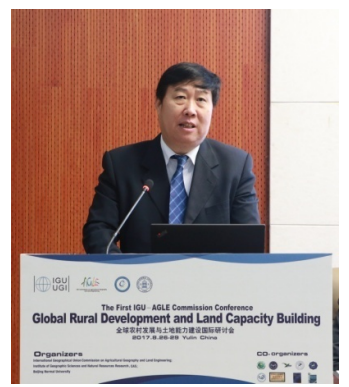

Bojie Fu

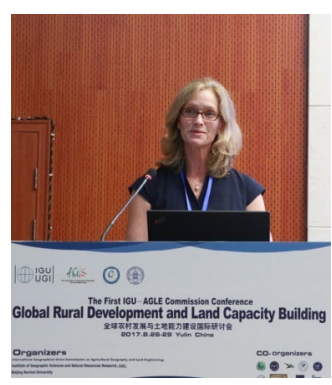

Holly Barcus

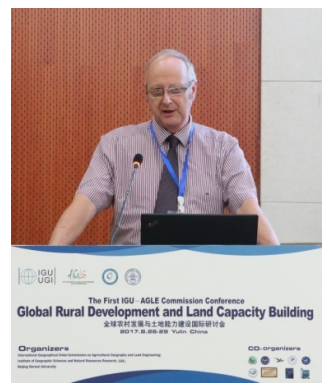

Guy M. Robinson

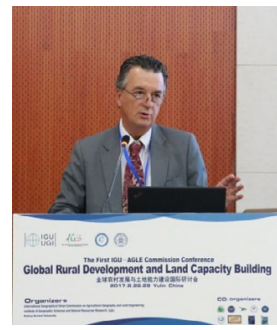

Hans Westlund

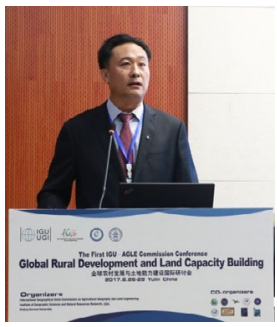

Yansui Liu

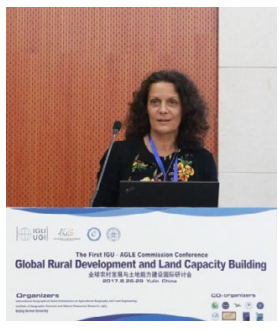

Brigitte Nougarèdes

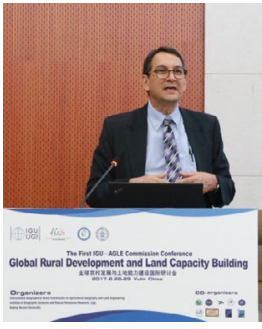

Bob Nanes

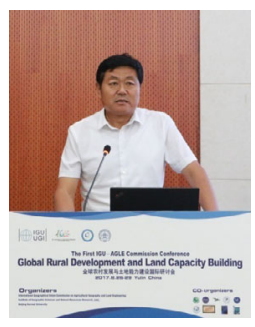

Yong Chang

Invited guests made keynote speeches

\section{Executive Committee Meeting of the IGU-AGLE}

Inaugural meeting of the IGU-AGLE executive committee was held in $27^{\text {th }}$, August, focusing on discussion of the mechanism and system improvement, setting up the planning and programming, conferences organization, construction of communication and networking platform, and other matters. Prof. Yansui Liu proposed that: (1) IGU-AGLE needs to further improve its mechanism and make clear division of labor and cooperation to form resultant force. IGU-AGLE will actively undertake the task of IGU, and take the initiative to undertake academic innovation and communication responsibility; (2) Development plan for the next five years should be scientifically made to strengthen cooperation and exchange programs with the other commissions; (3) Organizing international conferences, strengthening academic exchanges, and promoting disci- 
pline development and personnel training should be the focus of IGU-AGLE; (4) Strengthening the construction of IGU-AGLE network platform, creating convenient and efficient channels for academic communication, and promoting discipline development and personnel training. Michael E. Meadows highly praised the innovative work and achievements of IGU-AGLE since its establishment in December, 2016. He offered suggestions on further constructing the platform and promoting international academic exchanges and cooperation. He hopes that IGU-AGLE will continue to work in a scientific, rigorous, and responsible manner, strengthen close cooperation with other IGU commissions, and comprehensively promote the academic research and discipline development in global agriculture, rural transformation and land engineering. Members of the executive committee carried out the brainstorming, discussed the position and development orientation of IGU-AGLE and also proposed its near-term plans and long-term considerations which would lay a solid foundation for sustained rural development.

\section{Closing ceremony}

Closing ceremony was presided over by Dr. Yuheng Li. The conference has established Distinguished Scholar Award, Young Scholar Award, Outstanding Thesis Award, Conference Contribution Award and Special Contribution Award. The awards ceremony was held at the closing ceremony. Then, Yansui Liu read out the proposal of "Global Rural Plan". He congratulated the successful convening of the conference, summarized the academic exchange and panel discussion of the conference, and expressed his sincere thanks to the organizers, co-organizers and all the participants.

\section{Proposal of "Global Rural Plan"}

Based on expert consensus and suggestions, the "Global Rural Plan" was jointly launched by IGU-AGLE, IGU-CSRS, and IGU-LUCC. The proposed "Global Rural Plan" suggests that the geographers should take positive action and offer suggestions for effective implementation of rural revitalization program. The proposed "Global Rural Plan" calls for a series of actions: (1) To promote the establishment of the "Global Rural Plan" at the United Nations. It is very considered essential necessary to propose the theme of rural revival to counter the effects of urbanization across the globe; (2) To promote collaborations among the IGU commissions on Agricultural Geography and Land Engineering, Sustainability of Rural Systems, Land Use and Land Cover Change to bring the world's rural scholars together; (3) To hold the annual global meetings and regional conferences with a rural focus such as rural land in the countryside, agriculture, livelihoods and education; (4) To launch the joint scientific investigation of the socioeconomic, resources and environmental situations of villages of different areal types in the world, and to release a global world's rural development report; (5) To promote and intensify communications and collaborations with the World Bank, FAO, UNDP and UNEP; and (6) To mobilize resources to support villages in the least developed countries and to seek solutions for rural revival and sustainability. The "Global Rural Plan" is intended to make the world a better place.

\section{Post-conference field investigations}

To fully understand the problems of degraded land in Mu Us desert and make clear the barriers in agriculture development, post-conference field investigations were arranged for participants to excurse to red clay borrow pit at Qianwantan in Qinhe town in Mu Us desert, the experimental station on optimization engineering of modern agriculture, Yulin national agricultural science and technology park-the experiment station, and new rural development demonstration area - Zhaojiamao village. At the experimental station on optimization engineering of modern agriculture, scholars and researchers exchanged ideas extensively about the optimization engineering technology of land consolidation and seed selection of modern agriculture, investigated field com- 
parison test scheme and recent researches about implementing the order land consolidation and how to sow the improved varieties on the fertile soil. Experts including Michael E. Meadows, Guy M. Robinson, Hans Westlund, Bob Nanes, Brigitte Nougaredes, Rajendra P. Shrestha, Zhixiang She, etc., wrote inscriptions for the scientific design and test achievements. They encouraged the experimenters to make unremitting efforts, work more grass roots research, and take the exploration and innovation to advance the research of land consolidation, modern agriculture and rural integration development.

The success of the conference has offered an important platform for experts' communication in the research field of rural development and land capacity building, which has played an active guiding role in providing new ideas and developing new ways for international academic research and cooperation in the future. Participants reach a consensus that rural decline is a global problem, and focus of urbanization has increased in the cities, and less on the rural areas. It is urgent to further strengthen international cooperation and extensive exchanges on global rural development and land capacity building.

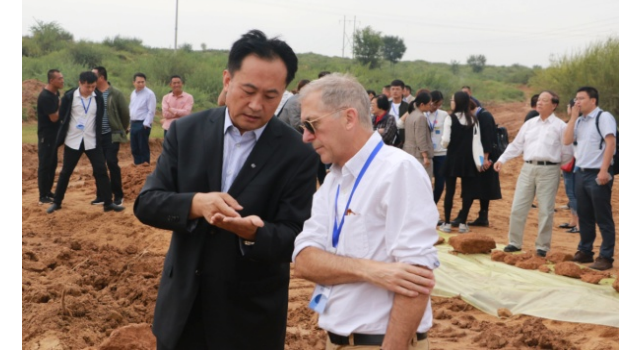

Visiting red clay borrow pit at Qianwantan

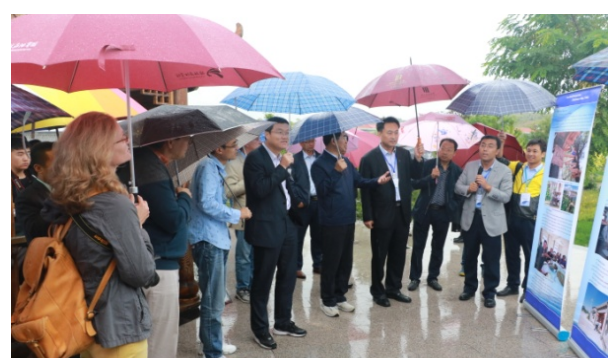

Visiting Zhaojiamao village

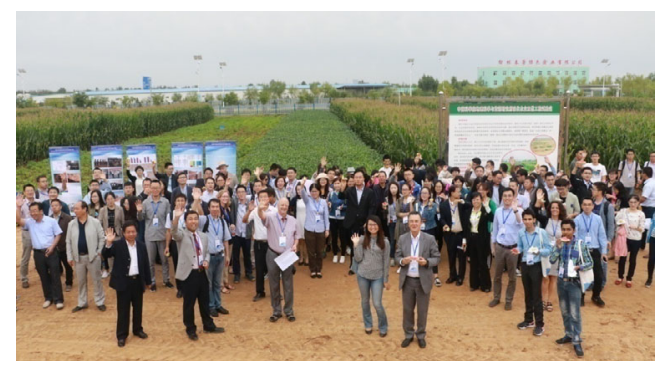

Visiting experimental station on optimization engineering of modern agriculture

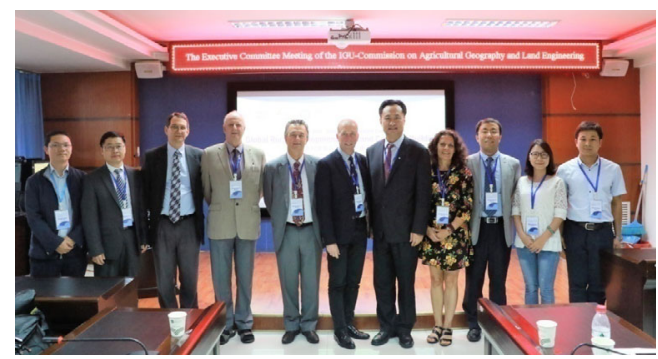

The Executive Committee Meeting of the IGU-AGLE

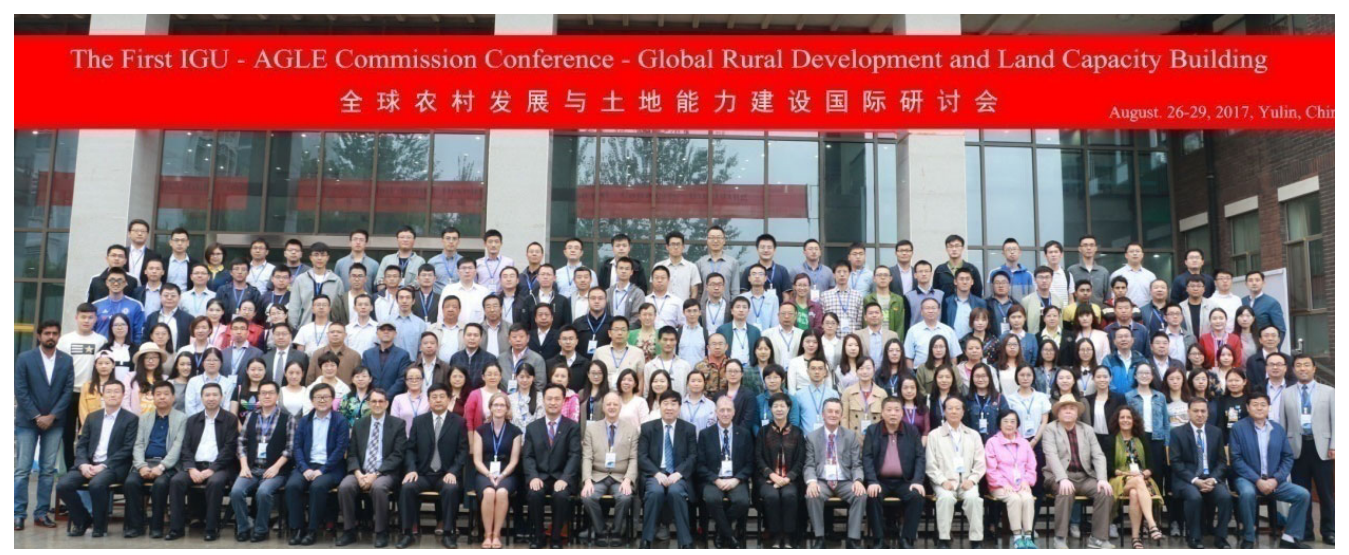

Group photo of the IGU-AGLE Commission Conference on Global Rural Development and Land Capacity Building 